\title{
4. Monitoring and evaluation of innovation policy
}

\subsection{INTRODUCTION}

Chapter 3 discussed existing innovation policies and strategies, and their sources. It introduced statistical measurement that supports research on the subject of innovation, influenced by policy that has been implemented. This chapter looks at the monitoring and evaluation of implemented innovation policy and how this is done. Four topics are covered: country reports; reviews of innovation policy conducted by independent experts; scoreboards that can be used to rank countries; and country ranking.

Country reports of innovation surveys can be used to support research on innovation (discussed in Chapter 3) and to promote a wide range of discussion of the findings from innovation surveys conducted in the country. Such discussion in statistical offices, policy departments, the business sector, and other sectors, including civil society, can influence subsequent surveys, analysis and policy development. The real advantage of producing clear and accessible country reports, and distributing them widely, is the development of an informed community that can offer constructive criticism of implemented innovation policy.

Innovation policy reviews are conducted by experts at the request of the country that has developed and implemented the innovation policy. The most recent example is the OECD (2019b) review of higher education, research and innovation for Portugal. The importance of such reviews is that they bring together a community of policy makers, users of the policy and statisticians, who can benefit from interacting with the experts that conduct the review.

Scoreboards gather data on countries from a variety of sources and produce indicators related to innovation. Some of these indicators come from direct measurement of innovation by innovation surveys, others deal with framework conditions. Examples are provided from the OECD, 
the European Commission, the Global Innovation Index (GII) and the African Innovation Outlook (AIO). Scoreboards can raise the discussion of innovation from a country level (country reports) to an international level and lead to the adoption of best practices by participating countries. Scoreboards can also be used for ranking of countries.

Ranking of countries is quite different from monitoring of implemented innovation policy as the ranking can have impact on the behaviour of the countries being ranked which may not help evaluate and improve innovation policy.

The country reports, policy reviews by independent experts and scoreboards, all deal with innovation in the business sector, with one exception, the EU public sector innovation scoreboard. It is presented, along with a brief discussion of household innovation, as an introduction to monitoring innovation in all economic sectors. This is discussed in Chapter 7 while this chapter looks at what is being done now.

\subsection{COUNTRY REPORTS}

\subsubsection{Some Examples}

EU Member States, and Iceland and Norway, conduct the Community Innovation Survey (CIS) every two years and report their findings to Eurostat, the statistical office of the EU. They may also produce country reports, an example of which is the UK report for the CIS 2014-16 released in 2017.

Outside of the EU, examples of country reports are found in Canada, which runs a survey on innovation and business strategy, and the US Science and Engineering Indicators 2018 (National Science Board 2018: Chapter 8).

An example of a report on a specific topic is the US InfoBrief (Kindlon and Jankowski 2017). The points were made in Chapter 3 (Table 3.1) that more firms innovate than do R\&D, but firms that do invest in $R \& D$ have a higher propensity to innovate. A more comprehensive discussion of innovation indicators is provided in Science and Engineering Indicators 2018 (National Science Board 2018: Chapter 8).

If $\mathrm{R} \& \mathrm{D}$ promotion is part of innovation policy, it is important to monitor the link between R\&D expenditure and innovation. If innovation policy is directed at firms that do not do R\&D, again, they should be monitored, along with firms that move to and from R\&D performance (Molotja et al. 2019). The paper by Molotja et al. (2019) examines the 
presence of firms in a ten-year period. The firms are classified according to their level of expenditure on R\&D performance and the number of years they are present in the ten-year period. There are two findings relevant to innovation policy. The first is that large spenders on R\&D performance are relatively few but have a high likelihood of being present for all ten years. The second is that most of the population is accounted for by small performers of R\&D that are present for one or two years in the ten-year period.

Innovation surveys and country reports are not just the prerogative of developed countries. In Africa, there have been two editions of the African Innovation Outlook (AU-NEPAD 2010; NPCA 2014) which have chapters on R\&D and innovation activities, and policies, in participating countries. These are closer to country reviews than scoreboards as the innovation activities of countries are deliberately not ranked. A third report was released in 2019 (AUDA-NEPAD 2019). A specific example of a country report is provided by Kenya (Ministry of Education, Science and Technology, Kenya 2016).

\subsection{COUNTRY REVIEWS}

Country reviews of innovation policy are provided by the OECD at the request of countries, [ the five most recent reviews are for Portugal (OECD 2019b), Austria (OECD 2018a), Kazakhstan (OECD 2017a), Norway (OECD 2017b) and Finland (OECD 2017c). Country reviews are also conducted by other international organisations such as the World Bank, UNIDO and UNESCO, through its Global Observatory of Science, Technology and Innovation Policy Instruments (GO-SPIN) programme.

While the methods used in the reports vary, the emphasis is on policy rather than statistical measurement and on what the countries are doing rather than on international comparisons. Scoreboards, in the next section, provide country comparisons.

\subsection{INTERNATIONAL SCOREBOARDS}

\subsubsection{Introduction}

International scoreboards vary in the indicators that they report, but they all provide a means of ranking the countries studied. In principle, this allows countries to review what they are doing and to improve activities 
that result in a low ranking. Whatever the cause, the ranking could be regarded as a warning which needs action. However, countries could be driven by the ranking rather than assessing their innovation system, reviewing that and committing resources that better serve the country than allocating the resources to moving up the ranking of a scoreboard. There is also a question about the extent to which indicators are linked. Action on one might have unexpected consequences for others.

In what follows, three scoreboards are discussed: the OECD Science, Technology and Industry Scoreboard 2017 (OECD 2017d), the European Innovation Scoreboard (EIS) (European Commission 2019) and the Global Innovation Index (Cornell University, INSEAD and WIPO 2019). The innovation that is presented in these scoreboards takes place in the business sector and there is limited reporting of direct measurement of innovation, but more on the framework conditions, introduced in Chapter 2 , for innovation to occur. There is also considerable coverage of $\mathrm{R} \& \mathrm{D}$, which is an innovation activity but not innovation unless the result of the R\&D is introduced on the market or brought into use by the firm (OECD/ Eurostat 2005). A comprehensive review of innovation scoreboards is found in Hollanders and Janz (2013).

While the examples in this section deal with business sector innovation, using the definitions of innovation in the third edition of the Oslo Manual (OECD/Eurostat 2005), there has been work done on innovation in other sectors, especially the public sector, discussed in Chapter 7 but without the advantage of a standard definition of innovation applicable in all economic sectors.

\subsubsection{OECD Science, Technology and Industry Scoreboard 2017}

The OECD 2017 Scoreboard highlights the digital economy and the technologies that are part of it. Specific discussions of innovation are found in Chapters 3 and 4 of the Scoreboard. The digitalisation of the economy is changing it and the ways in which innovation can happen. This is discussed further in Chapter 10 of this book.

Chapter 3 of the Scoreboard, 'Research Excellence and Collaboration', deals with collaboration leading to innovation. In most countries, collaboration is led by suppliers and clients of the firm that innovates while there is less collaboration with institutes of higher education or research institutions. There is a firm size effect as large firms have greater absorptive capacity and are more likely to collaborate with institutes of higher education or research institutions. SMEs are more likely to collaborate 
with suppliers and clients. The size effect also applies to collaboration with other organisations as part of work on innovation.

Chapter 4 of the Scoreboard, 'Innovation in Firms', provides a country comparison of innovative firms in information and communication technologies (ICT) manufacturing and information technology services for the reference period 2012-14 and notes that 74 per cent of ICT manufacturing firms innovated, compared with 51 per cent for all firms in manufacturing (OECD 2017d: 152). This has implications for analysing the digital economy while noting that the digital economy is much more than the ICT sector.

Data are provided to demonstrate the influence of firm size on innovation (OECD 2017d: 154) by type of innovation and by new to market product innovation. There is further analysis of size dependence of firms receiving public support for innovation (OECD 2017d: 159). The firm size dependence of innovation is an issue for the formulation of innovation policy of governments (Chapter 3).

The sources of the innovation data used in Chapters 3 and 4 are the OECD survey of national innovation statistics and the Eurostat Community Innovation Survey (CIS 2014). The point to note is that the OECD Science, Technology and Industry Scoreboard 2017 makes extensive use of the direct measurement of innovation while providing comments on the measurability of innovation.

\subsubsection{The European Innovation Scoreboard 2019 and the Regional Innovation Scoreboard 2019}

The European Innovation Scoreboard (EIS) 2019 (European Commission 2019) presents information on EU Member States and selected countries outside of the EU. The Member States are classified into four performance groups, based on their average performance scores as calculated with a composite indicator. There are four performance groups (European Commission 2019: 6):

1. Innovation leaders: Denmark, Finland, the Netherlands and Sweden

2. Strong Innovators: Austria, Belgium, Estonia, France, Germany, Ireland, Luxembourg and the United Kingdom

3. Moderate Innovators: Croatia, Cyprus, the Czech Republic, Greece, Hungary, Italy, Latvia, Lithuania, Malta, Poland, Portugal, Slovakia and Spain 
4. Modest Innovators: Bulgaria and Romania.

As with the OECD Science, Technology and Innovation Scoreboard 2017 , many of the indicators are not directly related to innovation but related to possible inputs and outputs of innovation. Human resource information and publications and patents are examples.

Of the 27 indicators used in the Scoreboard, six are direct measures of innovation, or innovation activity, taken from the CIS. The six are described in Annex E of the EIS. Each indicator has a number and the CIS-based indicators, with their indicator numbers, are the following:

2.2.2 Non-R\&D innovation expenditures (percentage of turnover)

3.1.1 SMEs introducing product or process 8 innovations (percentage of SMEs)

3.1.2 SMEs introducing marketing or organisational innovations (percentage of SMEs)

3.1.3 SMEs innovating in-house (percentage of SMEs)

3.2.1 Innovative SMEs collaborating with others (percentage of SMEs)

4.2.3 Sales of new to market and new to firm innovations as percentage of turnover.

Indicators 3.1.1, 3.1.2, 3.1.3 are direct measurements of innovation in SMEs. Indicator 3.2.1 captures the effect of networks and collaboration. Indicators 2.2.2 and 4.2.3 apply to firms of all sizes and deal with the expenditure on innovation activities that are inputs to innovation (2.2.2) and sales of product innovation that are outputs of innovation. Data on SMEs are relevant because SMEs form the majority of firms in most countries and can play a vital role in innovation, for example, as developers of new ideas and as adopters of new technologies (Hollanders and Janz 2013). SMEs also tend to be single establishment firms which avoids the multi-establishment issues of analysing the data for large firms.

Countries are ranked by findings in the Scoreboard and the ranking may influence policy development. This gives rise to challenges of the methodology (Edquist and Zabala-Iturriagagoitia 2018) and discussion in governments and civil society.

The Regional Innovation Scoreboard (RIS) 2019 is an extension of the EIS which covers 239 regions in 23 EU countries, Norway, Serbia and Switzerland. It uses 18 of the 27 indicators in the CIS and the principal finding is that Europe's most innovative regions are in the most innovative countries. 


\subsubsection{Global Innovation Index (GII) 2019}

The Global Innovation Index (Cornell University, INSEAD and WIPO 2019) has been in place since 2007 and provides country reviews and rankings that are highly influential. In addition to its annual indicator report, the GII addresses a theme, for 2019, Creating Healthy Lives - The Future of Innovation, and for 2018, Energising the World with Innovation. It is in the theme chapters that possible innovations are presented.

The 80 GII indicators deal with framework conditions for innovation and are grouped into seven themes.

1. Institutions

2. Human capital and research

3 Infrastructure

4 Market sophistication

5. Business sophistication

6. Knowledge and technology outputs

7. Creative outputs.

Each theme has two subsections where the indicators are described, and their sources noted. While the statistical measurement of innovation is not discussed, there is enough information on topics related to innovation to support the monitoring and evaluation of innovation policy.

\subsubsection{Scoreboard Summary}

This section has presented three types of scoreboard: the OECD Science, Technology and Industry Scoreboard 2017 which uses and presents statistical measures of innovation from a number of sources, the EU Innovation Scoreboard 2019 which makes use of CIS results in the six innovation indicators (of 27) focused on innovation in SMEs, the Global Innovation Index 2019 (Cornell University, INSEAD and WIPO 2019) which does not address statistical measurement of innovation but provides 80 indicators of framework conditions which could support or impede innovation. Examples of innovations are provided in the chapters on the theme of the year, Creating Healthy Lives - The Future of Innovation, in the case of the 2019 GII. 
There are other scoreboards but these three provide examples of different approaches to innovation indicators derived from measures of innovation that take place in the business sector.

\subsection{RANKING}

Ranking is an outcome of scoreboards and it can have negative impacts. A country that is low in the ranking may have difficulty attracting a skilled labour force. As already discussed, countries may allocate resources to try to improve their ranking, to the detriment of their economy and society.

If countries are going to respond to scoreboards and their rankings, they should convince themselves of the legitimacy of the scoreboards and their contribution to society (Davis et al. 2012). This is not an issue for the scoreboards reviewed in this chapter, but it is an important consideration as economies change and new scoreboards appear. Von Bogdandy and Goldmann (2012) provide an illustration of the power of scoreboards.

\subsection{INNOVATION BEYOND THE BUSINESS SECTOR}

For the measurement of innovation in the business sector, there was the definition of innovation from the third edition of the Oslo Manual (OECD/Eurostat 2005). There was no comparable definition for innovation in the general government sector or the public sector (general government and public institutions), an issue discussed in Gault (2018a), and resolved in the fourth edition of the Oslo Manual (OECD/Eurostat 2018).

The absence of an internationally accepted definition of innovation did not prevent work on understanding innovation in the public sector. Some of the projects are discussed in Chapter 7 of this book, including the European Public Sector Innovation Scoreboard 2013 (EPSIS) (EC 2014) and the OECD Observatory of Public Sector Innovation (OPSI). The Handbook of Innovation in Public Services (Osborne and Brown 2013) provides a comprehensive review of innovation in the public sector. The general definition of innovation (OECD/Eurostat 2018), applicable in the public sector, is also discussed in Chapter 7.

From a historical perspective, it is instructive to see the evolution of the definition of innovation for use outside the business sector going back at least a decade. In the Nordic countries, there was the 'Measuring Public Innovation in the Nordic Countries' (MEPIN) project (Bloch 2010a, 
2010b, 2013; Bloch and Bugge 2013) which developed a definition for use in measuring innovation in the public sector. This was an important project as it led to a proposal in 2014 to the OECD Working Party of National Experts on Science and Technology Indicators (NESTI) for the development of a manual, like the Oslo Manual, that would provide guidance on measuring and interpreting data on public sector innovation. The timing was not ideal as the revision of the Oslo Manual, leading to the fourth edition, was scheduled to begin in 2015, the year in which the seventh edition of the Frascati Manual (OECD 2015c) was published.

At the same time, there was a project in Finland to measure innovation by household sector and individuals. The project was led by Jari Kuusisto for Finland and Eric von Hippel led the consultants' team (Kuusisto et al. 2013; de Jong et al. 2015). Part of the motivation was to find a culture of innovation that could support household innovation and the growth of the innovators into large businesses providing jobs and economic growth. This was a successful project but the activities being measured did not align with the definition of innovation in the third edition of the Oslo Manual. Individuals and households could develop new or significantly improved products but introducing them on the market was not yet a consideration.

The discussion of this problem led to a paper, Gault (2012), in which a small change to the Oslo Manual definition of innovation was proposed. The proposal was to replace 'introduced on the market' for a product innovation with 'made available to potential users' in paragraph 150 of OECD/Eurostat (2005). If this was done, the new or significantly improved product developed by the household, or the individual, was a product innovation if it was made available to potential users. From the perspective of official statistics, there were three options for the innovator to make the product available. The product could be made available to

1. a producer, demonstrating the improvement to the product;

2. an existing business or a new business of the innovator;

3. a community of practice or a peer group.

The first two options would be captured in a CIS if the producer, or the innovator's business, had ten or more employees. The third option would not appear in official statistics, but it was a means of including households, or individuals, as innovators. A more detailed discussion of user innovation and official statistics is found in Gault (2016). 
It was also evident that such a change to the definition could apply to the measurement of innovation in the public sector and this led to the broader question of whether there could be a definition of innovation applicable in all economic sectors. A discussion paper was provided to the team working (Gault 2015) on the revision of the Oslo Manual, leading to the fourth edition.

This historical review demonstrates that the definition of innovation, for measurement purposes, is still evolving, as are the measurement activities that are governed by the definition.

\subsection{CONCLUSION}

This chapter has reviewed the means for monitoring and evaluating implemented innovation. These include country reports, based on innovation surveys, country reviews conducted by experts on innovation policy, the use of scoreboards for ranking of countries. All of these can be used to monitor and evaluate the state of innovation in the business sector in participating countries. Public sector innovation was introduced to set the stage for discussion, in Chapter 7, of a general definition of innovation applicable in all economic sectors.

\section{NOTES}

1. See https://www.gov.uk/government/statistics/uk-innovation-survey-2017 -main-report (accessed 17 March 2020).

2. See https://www150.statcan.gc.ca/n1/daily-quotidien/190326/dq190326b -eng.htm (accessed 17 March 2020) and references provided there.

3. See https://www.oecd.org/innovation/oecd-reviews-of-innovation-policy .htm (accessed 17 March 2020) for recent examples.

4. An example is a review of Viet Nam done with the OECD. https:// www.worldbank.org/en/country/vietnam/publication/a-review-of-science -technology-and-innovation-in-vietnam (accessed 17 March 2020).

5. An example is Tanzania, see https://www.unido.org/sites/default/files/2011 -04/Tanzania_0.PDF (accessed 17 March 2020).

6. This is described in https://en.unesco.org/go-spin (accessed 17 March 2020).

7. See http://www.oecd.org/sti/inno-stats.htm (accessed 17 March 2020).

8. The use of composite indicators is discussed in OECD/Eurostat (2018), para. 11.23 and Box 11.2.

9. 'Process' here is defined in the third edition of the Oslo Manual (OECD/ Eurostat 2005), not in the fourth edition (OECD/Eurostat 2018) where 'process' is different. 
10. See https://ec.europa.eu/growth/industry/innovation/facts-figures/regional en (accessed 17 March 2020).

11. Business sector innovation was discussed for about 15 years before there was agreement on what could be accepted as a definition of innovation for measurement purposes, leading to the first edition of the Oslo Manual (OECD 1992). See Chapter 6 of this book.

12. See https://op.europa.eu/en/publication-detail/-/publication/fe2a3b4b -3d7e-444d-82bc-790a0ab33737 and https://ec.europa.eu/growth/content/ innovation-public-sector-0_en (both accessed 17 March 2020). 